\title{
Faculty Mentoring in Eritrean Institutions of Higher Education: A Missing Academic Ingredient for Early Career Academics
}

\author{
Zecarias Zemichael \\ Asmara College of Education \\ E-mail: zzecaria@gmail.com
}

\begin{abstract}
Cultivation of professionalism and dispositional values of junior faculty members/early career academic in higher education institutions is a global challenge. This paper explores how Graduate Assistants are mentored at work in the higher education institutions in Eritrea. The paper assesses the institutional significance and challenges of mentoring the Graduate Assistants in the context of Eritrean higher education institutions. The research involved the leadership of the colleges, the senior faculty members and the Graduate Assistants. Quantitative and qualitative data were gathered through a Likert scale questionnaire and in-depth interviews. The findings show that Graduate Assistants receive poor professional mentoring at the higher education institutions. A large number of early career academic revealed a need of serious professional molding to effectively shoulder more responsibilities at the colleges. The early career academic are looking for genuine advisement for career aspiration and professional development opportunities. The colleges' efforts to ensure recognition, delegation, accountability and encouragement of Graduate Assistants are not yet systematic and hardly materialized in practice. The higher education institutions are required of a firm institutional commitment to sharpen the junior staff's professional competence in teaching and research through mentoring. Based on the findings, alternative mentoring strategies to mentor early career academic at the higher education institutions are forwarded.
\end{abstract}

Keywords: early career academics, graduate assistantship, mentoring, stimulation, inspiration

DOI: $10.7176 / \mathrm{JEP} / 11-15-01$

Publication date:May $31^{\text {st }} 2020$

\section{Introduction}

The community of higher education institutions (HEI) is a learning community where the students and academics learn from each other. In the workplace, junior academics learn from the senior faculty members to improve their personal and professional dynamism. In HEI, human resource is the most valued asset that determines the achievement of its objectives. Creating a favorable work environment to promote a sense of purpose in employees that goes beyond a simple exchange of rewards for efforts at work is a key element of organizational success. HEI can systematically enforce such an institutional motto to help faculty move beyond personal interests for the good of their colleagues, institutions and society. However, the cultivation of professionalism and dispositional values of ECA in HEI is a global challenge. Amid the global challenge of economic crisis, HEI are required to become adaptive in today's competitive world through strategic and coherent approach to manage the human capital (Armstrong, 2006).

In academic institutions, successful dynamism of professional and collegial positive relationship between senior and ECA can be fundamentally shaped through mentoring (Ehrich, Hansford and Tennent, 2001). Faculty mentoring is a mutual engagement of senior and ECA for professional growth and strengthening of institutional capacity. Cossa, Buque and Fringe (2016) noted that "mentorship is one of the most important processes to professionals in the beginning of their career" (p. 1774). Mentoring is defined as a meaningful relationship between a mentor and mentee (Inzer and Crawford, 2005). The paper treats mentoring ECA as a deliberate coaching and leading by example to professionally transform them. Effective mentoring wins the hearts and minds of the mentees, encouraging them to enlarge their vision and develop clear understanding of their purpose to cultivate enduring and self-perpetuating professional behavior congruent with organizational beliefs, principles, values and strategic objectives (Inzer and Crawford, 2005). According to Zellers, Howard, \& Barcic (2008) mentoring is seen as "a reciprocal learning relationship characterized by trust, respect, and commitment in which a mentor supports the professional and personal development of the mentee by sharing his or her life experiences, influence, and expertise" (p. 555).

Mentoring the GAs through professional engagement with the senior faculty serves as a learning opportunity and staff development initiative in the institutions. The National Board for Higher Education (NBHE) guidelines in Eritrea stipulate that senior faculty members are expected to play leading role in guiding the GAs in teaching, research and other activities in their respective disciplines. The senior faculty are required to undertake supervisory role and demonstrate commitment to promote the professional excellence of the ECA. Findings reveal that mentoring initiative boosts the professional and psychological functions of both the mentee and their mentors (Parise and Forret, 2008). According to Fuller et al. (2008), the full circle of mentoring becomes successful when a mentee becomes mentor "to give back to the system that promoted his/her career" (p. 4). 
In HEI, collegial stimulation and inspiration cannot be nurtured in the absence of a positive work environment that promotes the spirit of teamwork. The study explored the views of the leaders of the colleges, the senior faculty members and GAs about mentoring affairs within the HEI. The paper examined the personal and institutional benefits of mentoring in HEI in Eritrea. The attitudes of the faculty members linked to the support systems for the mentorship of ECA and Graduate Assistants' $\left(\mathrm{GAs}^{1}\right)$ state of mentoring affairs at the HEI are emphasized. It addressed how the GAs are mentored at work, the key challenges of mentoring the GAs and possible alternatives of mentioning relationships to professionally stimulate and influence the ECA at the HEI. The paper assessed the collegial encouragement of the GAs by the senior colleagues as well as the leadership to reinforce their commitment and striving hard for professional and institutional development. It paper shed light on the GAs' inspiration due to the senior faculty's modeling, guiding and influencing to persuade and promote their professional confidence and creativity to catalyze personal and institutional capacity.

The world witnessed high rate of higher education expansion in the last four decades "with Sub-Saharan Africa recording the highest growth rate than any other region" (Alabia and Abdulaib, 2016, p. 1754). In terms of academic qualification of faculty members, colleges and universities in Africa are inundated by ECA. In line with the access to tertiary education, the quality of staff that significantly determines the quality of higher education practices is a contemporary issue of debate in the developing world including Eritrea. HEI in Eritrea recruit young and inexperienced bachelor holders working at the colleges as GAs aspiring to grow into tenured faculty in the colleges. The graduate assistantship creates a window of opportunity for the GAs to pursue their dreams of postgraduate studies, which is not privately affordable for many of them. The graduate assistantship creates a window of opportunity for the GAs to pursue their dreams of postgraduate studies, which is not privately affordable for many of them. In this context of high education staffing, mentoring becomes a career development tool in supporting the ECA in the HEI. Mentoring these ECA in teaching and research is preparing them for the demanding postgraduate studies. Such capacity building initiatives in HEI help the ECA their self-confidence, self-efficacy and academic skills (Teferra, 2016; Thomas et al., 2015; Law et al., 2014; Metzger et al., 2013). In line with these principles, the paper endeavored to answer the following major research questions:

1. What are the benefits of mentoring at HEI in Eritrea?

2. How is the state of mentoring situation for the GAs at the HEI?

3. What are the challenges hindering effective mentoring at the HEI?

4. What type of mentioning relationship is logically effective to mentor the ECA?

\section{Theoretical framework}

There is no empirical information about the mentoring situation of faculty members at HEI in Eritrea. However, the absence of relevant literature on faculty mentorship seems a global challenge. Research evidences show that "very few studies have been conducted so far on the mentoring or protégé experiences of academicians in the university setting" (Anafrta \& Apaydın, 2016, p. 22). Teferra (2016) noted the influx of "average academics" into the HEI has resulted in noticeable strain of academic exercise in the tertiary education of the African continent more than any other times. He further remarked that:

For all the debates and dialogues on 'massification' and revitalizing of higher education in Africa, little to no attention has been afforded to the state of the teaching praxis of academics in the institutions. Most academics are not known to have been trained to teach; and they are expected to catch up on the job. (p. 1735)

The existing staffing situation of the Eritrean HEI is not different from the realities of many other African colleges and universities. In the Eritrean HEI, the academics are predominantly inexperienced national and expatriate junior faculty. A large number of ECA at the colleges (Fig. 1) are holding major academic responsibilities without required training. In a similar study about ECA integration in to the teaching career of HEI in Ghana, Teferra (2016) noted the "lack of a policy requirement for teaching competence prior to entering the academic field" (p. 1754) in the country. In this context, coaching the ECA staff in a vibrant mentoring collaboration at the colleges is an alternative strategy to face the inevitable academic and institutional mediocrity.

Therefore, workplace experiences are proven shaping tools for new staff members in HEI, because the senior faculty members shape and influence junior colleagues by sharing their interests and career aspirations through mentoring programs (Petryk, 2000). Mentoring practically propagates the principles of social learning model of Bandura (1977) emphasizing the "importance of positive reinforcement" (Agunloye, 2013) to shape the faculty's knowledge, attitude and skill at work place. Hence, the effect of role modeling holds a central place in mentormentee relationship. A vibrant mentoring between the junior and senior faculty members in HEI promotes the collegial, social and professional cohesion at work. The interpersonal and professional synergy between the ECA and the senior faculty members at colleges and universities is a requisite to successful mentoring of career development at the institutions. Agunloye (2013) noted that "as a social learning approach, mentoring finds strong

\footnotetext{
${ }^{1}$ GAs are first degree holders (Bachelors) teaching at the HEI
} 
relevance in building leadership skills among the disadvantaged and in situations where resources for professional growth and development are limited" (p.959). Boyden (2000) noted that higher education leaders are "challenged to be creative in their approach to faculty development programs in the face of shrinking resources" (p. 104). Sustainable faculty development and institutional transformation in higher education development entails the genuine cultivation and "integration of research, teaching and mentoring activities" (Whittaker \& Montgomery, 2014, p. 266).

\section{Methodology}

The study used survey research method to understand the ECA's mentorship in the Eritrean HEI context. Multiple data collection techniques of in-depth interviews and questionnaire, desk review of higher education reports and policy documents were used to triangulate the data analysis of the study. The study participants include Deans of 7 colleges, 32 senior faculty members and 133 GAs from the 7 colleges. The Deans and the senior faculty members were contacted through in-depth interviews and the GAs filled self-administered questionnaire. Thus, quantitative and qualitative data were collected pertaining to the implication of the current state of mentoring situation for the GAs, institutional benefits of mentoring and the challenges hindering effective mentoring in the HEI in Eritrea. The questionnaire was pilot tested and administered for the GA participants after necessary amendments were made. The study also used secondary data pertaining to institutional reports and policy documents from the colleges and the board of HEI.

A mixed approach of qualitative and quantitative data analysis is used to analyze the data. The audio-taped interviews were carefully transcribed. The qualitative data from the in-depth interviews were thematically organized to answer the major research questions of the study. On the other hand, One-way ANOVA is used to analyze the quantitative data and comparing the views GAs from the different colleges. The research was conducted respecting the ethical standards of social science research. The research project was approved by the researcher's institution of affiliation. The permission of the host institutions and the participants' full consent to participate in the study were confirmed before the data collection process.

\section{Findings}

The key qualitative and quantitative findings of the research gathered from different sources were summarized based on the major identified themes of the data and coherently presented to answer the major the research questions of the study. The need for mentoring the GAs at the Eritrean HEI is very visible . There is huge number of GAs shouldering crucial responsibilities at the HEI; the GAs are teaching without trained to teach. The GAs are looking for guidance and coaching in research through professional collaborative teamwork of senior and ECA. The key indicators of the benefits of mentoring the GAs from the data include mentoring promotes leading the GAs by example and HEI need to mentor the GAs to face institutional limitations.

Table 1: GAs' views of mentoring realities in the HEI

\begin{tabular}{lcccc}
\hline & \multicolumn{3}{c}{ Responses } \\
\cline { 2 - 5 } Items & $\begin{array}{c}\text { Strongly } \\
\text { disagree }\end{array}$ & Disagree & \multicolumn{2}{c}{$\begin{array}{c}\text { Strongly } \\
\text { agree }\end{array}$} \\
\hline The seniors lead the GAs by example & 40 & 70 & 21 & 2 \\
A senior staff regularly supervises my progress & 70 & 57 & 3 & 3 \\
I am mentored by the seniors on professional ethics & 41 & 57 & 32 & 3 \\
I am mentored by the senior faculty on research skills & 50 & 61 & 18 & 4 \\
Junior faculty mentoring is flourishing in the colleges & 59 & 54 & 20 & 0 \\
\hline
\end{tabular}

$N=133$ and the 'neutral'option was deliberately omitted after pilot testing the questionnaire.

The above Table summarizes the existing state of GAs' mentoring at the HEI. Mentoring is not common practice at the academic institutions. The GAs are missing the leading by example for professional ethics, development of research skills and professional supervision. In a nutshell, ECA mentorship is not flourishing at the colleges. 
Table 2: One-Way ANOVA results of GAs' professional stimulation, inspiration and mentoring

\begin{tabular}{llccccc}
\hline \multirow{2}{*}{ Variables } & Sum of & Mean & & Sig. \\
\hline Professional stimulation & GA Groups & Squares & df & Square & F & .939 \\
for GAs & Between Groups & .091 & 3 & .030 & .134 & \\
& Within Groups & 29.103 & 129 & .226 & & \\
GAs' inspiration & Total & 29.194 & 132 & & & .416 \\
& Between Groups & 1.090 & 3 & .363 & .955 & .381 \\
Mentoring for GAs & Within Groups & 49.085 & 129 & .381 & \\
& Total & 50.176 & 132 & & & .062 \\
& Between Groups & 1.654 & 3 & .551 & 2.500 & \\
\hline
\end{tabular}

p is significant at 0.05 .

Table 2 represents the views of the groups of GAs from different colleges on the GAs' professional stimulation, empowering practices to inspire their professional aspirations and dispositions as well as the ECA mentoring practices at the colleges. The data revealed that there is statistically significant difference among the colleges in their failure to mentor the ECA. The major barriers of mentoring the GAs forwarded by the participants show that in all the IHE:

- Very few senior faculty presumed to mentor the ECA

- Mentoring junior faculty as a concept is underdeveloped

- Internal institutional capacity of mentorship is weak

- There is lack of mentoring tradition at the colleges

- Both the senior and the ECA are blamed for not acting proactively to work in teams

- Gaps were observed between policy and practice with regard to promoting the ECA Fig.1: Staff on ground in the Eritrea Institute of Technology (EIT) by academic rank

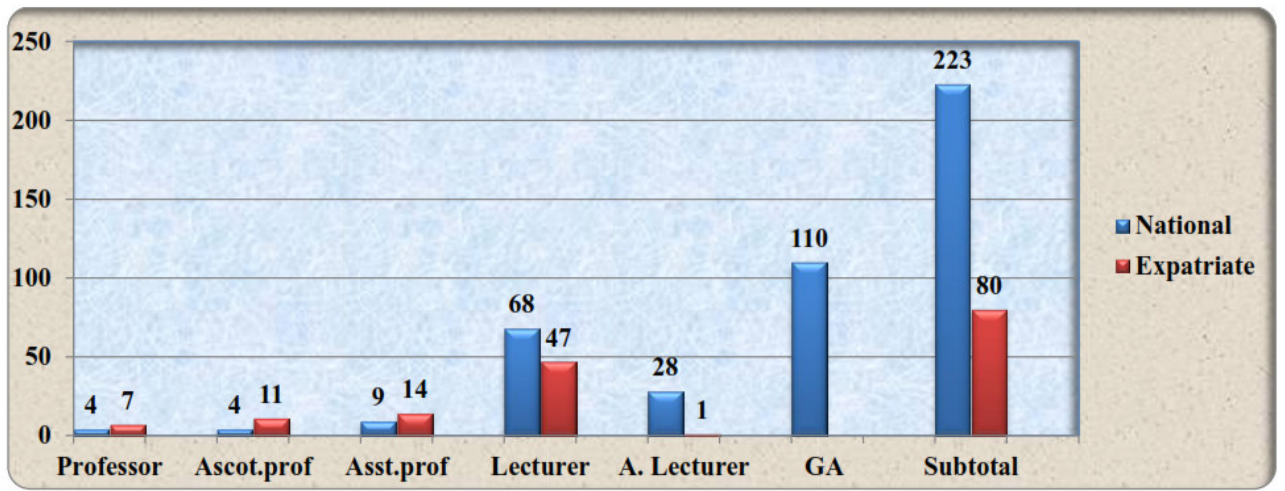

Source: Adapted from EIT (Semester I, Academic Year 2017/2018)

The bar chart shows an institutional report of national and expatriate faculty by their academic rank in three colleges. As the academic rank increases, the number of experienced professors presumed to mentor the GAs decreases, especially for the national staff (Fig. 1). The colleges are overwhelmed by ECA looking for professional mentoring.

Table 3: GAs' perception of their work experiences

\begin{tabular}{lcccc}
\hline & \multicolumn{4}{c}{ Responses } \\
\cline { 2 - 5 } Items & Strongly disagree & Disagree & Agree & Strongly agree \\
\hline GAs are not properly treated in the colleges & $10 \%$ & $23 \%$ & $32 \%$ & $35 \%$ \\
The leadership negatively affected GAs' career plan & $8 \%$ & $23 \%$ & $41 \%$ & $28 \%$ \\
Working as a GA should not exceed two years & $3 \%$ & $3 \%$ & $27 \%$ & $67 \%$ \\
I have no regrets about the years I worked as a GA & $8 \%$ & $11 \%$ & $43 \%$ & $38 \%$ \\
\hline
\end{tabular}

$\mathrm{N}=133$

The participants agreed that the ECA are not properly treated. Blaming the leadership for the ECA's hazy professional career plan at the colleges, the participants agreed that the working as a GA at the colleges should not exceed two years.

\section{Discussion}

The discussion section focuses on the institutional benefits of mentoring, the state of mentoring the GAs, the challenges hindering effective mentoring and viable mentioning strategies relevant to the context of the Eritrean 
HEI are discusses in detail. Mentoring practice in leadership development has long history in the private sector (Kee and Newcomer, 2008). On the contrary, HEI are described as institutions "which neither encourage nor discourage faculty ... after recruitment" need to integrate a "strategy to meet the needs of both individual faculty development and the redirection of the institutional support system" (Wunsch, 1993, p. 352-3). Hanover Research (2014) noted that mentoring is not new phenomenon in the context of HEI and the Collaborative on Academic Careers in Higher Education (2014) reported that faculty mentoring gained attention in academic institutions recently.

\section{Higher education institutions and mentoring early career academics}

Mentoring has myriad personal and institutional benefits (Brown, Davis and McClendon, 1999); it is a tool to enhance career functions and long-term investment in personal and organizational development. Mentoring contributes a lot to the professional development of the ECA and enhancement of institutional capacity building. The senior and the junior faculty participated in the study emphasized the significance of mentoring for emboldening the teaching, research, service capacity and career development orientation of the ECA. Mentorship in HEI has the nature of transforming individuals, institutions, working conditions and challenges into opportunities in mitigating professional and occupational problems of inexperienced faculty (Law et al., 2014). Research findings show that mentoring shapes the ECA's teaching efficiency in higher education (Subbaye and Dhunpath, 2016). According to Boice (in A guide for mentors and mentees), University of Maryland, 2008), "new faculty receiving mentoring find adaptation to their new job less stressful and are better teachers and more productive scholars."

The role of senior faculty members in shaping the GAs' professional excellence highly depends on the nature of collegiality. ECA gain new skills, establish new relationships, greater ability to meet career and institutional goals. The interviewees unanimously appreciated the role of mentoring the ECA to ensure quality teaching and research in HEI. Mentoring ECA promotes the psychological support system and social networking to important figures in the institution. The interaction shapes the GAs' perception of their work atmosphere, the quality of their task performance, career plans and boosts their self-esteem. Ultimately mentoring elevates the GAs' professional growth as educators and researchers to shoulder institutional and national responsibilities. Professional deliberations and discourse between the senior faculty and the GAs as part of coaching and mentoring can stimulate inquiry and critical thinking to broaden the GAs' professional vision in line with the institutional mission. ECA need encouraging, criticizing, challenging, guiding and prompting their enthusiasm to envisage beyond personal interests. Broadening the personal and institutional vision in the hearts and minds of the GAs is nurtured through professional stimulation at work. Thus, the mentoring dynamics in HEI is the tool of faculty empowerment and scholastic success (Hansford and Tennent, 2001).

The seniors are indispensably expected to "act as supporters, motivators, inspirations, role models, and mentors" (Sutherland and Petersen, 2009, p.30). Inspiration in HEI is often contagious among colleagues of different academic rankings and their students too (Clarke, Kenny and Loxley, 2015). Thus, mentoring the ECA creates an opportunity for them to serve as models of excellence for the undergraduate students. In academia, mentorship of ECA is a long-term solution in the face of personal and institutional challenges. It is an instrument of symbiotic professional to address ECA's professional concerns. The magnitude of the influence of better mentorship and support is magnified when inspired GAs in turn positively contribute towards the student community.

Successful mentoring programs promote partnership and teamwork in teaching and research irrespective of gender, age, rank, and discipline in HEI (Boyden, 2000). The findings revealed that in the dynamics of faculty mentoring, mentors can get professionally stimulated while interacting with bright and energetic ECA. The seniors get satisfaction from their supportive contributions and enhance their systematic and critical reflection. The senior faculty's renewal of career ambition ignited by the experiences of seeing the fruit of their efforts and their collegial interaction enhances their professional identity. Furthermore, the mentors gain trusted junior allies and their contributions get recognition within the organization and beyond. In addition, mentoring of the ECA results in ethically and professionally stronger, inspired faculty and a better quality of performance. The great Chinese philosopher Confucius (551-479 BCE, in Mcdevitt, 2007) appreciated the paramount role of leadership in mentoring one's subordinates. Confucius further noted employees shaped and mentored by benevolent mentors would be best suited to rule. Mutual stimulation and elevation as the result of mentoring converts leaders to moral agents and followers to next generation leaders (Burns, in Bolden et al., 2003).

Taking the quality of academic rank of the academics at the HEI in Eritrea in to account, professionally empowering the existing junior faculty of the colleges is an institutional task that cannot be shelved. Through wellorganized mentorship programs and genuine partnership strategy between the colleges' management system and the faculty members, it might be difficult but not impossible to work with GAs to rewind any threat into an opportunity in the HEI in Eritrea. 


\section{The graduate assistants' mentoring state of affairs at the higher education institutions}

Mentoring GAs is not as easy a task as it sounds (Waxman, Collins and Slough, 2009), because "mentoring is very complex" business (McKimm, Jollie and Hatter, 2007, p. 1). A college dean illustrated that his college attempted to affiliate each GA to a senior instructor for mentoring purposes. However, it was a vain effort because the affiliation led to confrontation instead of cooperation between the senior faculty members and the GAs. The dean blamed both the senior faculty and the GAs for the failure. He indicated that some seniors lack the requisite expertise and others reluctantly say "I want to be on my own. Why team teaching? Why should I affiliate with a junior and be at a strain?"

The mentoring capacity of the HEI is far below the expectation of the GAs. The participants acknowledged that most of the master's holders working in the HEI still need mentoring to mentor the GAs (Fig. 1). Furthermore, the GAs had limited expectations from of the unmotivated national senior staff. A GA described "majority of the expatriate faculty are "negligent" and indicated that regardless of their academic rank, only a few of them have mentoring qualities. A dean of a college noted that in some areas there are GAs better than some of the high academic rank expatriate faculty. He elaborated that "despite the expats constitute high percentage of the "qualified academic staff,' one can ask who will mentor who; otherwise, it will be a reverse mentoring." The idea that "any senior person can mentor a junior person" (Brown, Davis and McClendon, 1999, p. 107) seems logical but it is not always practical.

The readiness and willingness of the GAs to find their mentors is a major factor in mentoring. Attractive opportunities outside the HEI can pull ECA, but the lack of harmonious organizational support can drive them out of academia (Fuller et al., 2008). There is "reluctance from the GAs to approach the seniors" in need of professional mentorship and coaching (a dean of a college). The GAs' personal goals, ambitions and efforts contribute to their inspiration or frustration. The GAs' curiosity and initiative to professionally flourish as educators is crucial. A senior instructor said that the GAs' inspiration starts well in the beginning and naturally declines through time as the result of both their own internal qualities and external factors. The deans of the colleges explained that most of the GAs frustrations resulting from delays of postgraduate scholarships. The GAs' "goals and sources of inspiration will profoundly affect what kind of a teaching assistant" they become (Petryk, 2000, p. 4). One of the GAs noted that "vision is personal, regardless of seniority; the GAs need to have zeal and energy to turn their vision and goals into realities."

Despite all the compelling needs, little attention had been given to the process of promoting the massive number of GAs and their capacity to live up to the standards of universities and colleges. The colleges do not have a culture of mentoring programs as a means of shaping the attitudes, interests and professional capacity of the ECA. The GAs poorly rated the quality of the professional guidance and mentoring support they receive in the colleges. In line with the findings of Osman and Hornsby (2016) and Udegbe (2016), the ECA did not appreciate the professional escorting expected from the senior faculty within their institutional context. The participants implied that the numbness of institutional leadership to stimulate and inspire the promising GAs at the colleges has long-term side effects on different dimensions. It will be costly for the colleges continue to ignore responding to the mentoring needs of the GAs, the colleges will linger to struggle with academic mediocrity. The GAs did not admire the professional stimulation and the consequential inspiration they had after recruitment in the HEI. The nature of faculty inspiration in the colleges was described as in a "state of inertia." The GAs were professionally bored more than inspired working in the HEI.

The GAs realized that there is lack of professional stimulation, inspiration and mentorship of ECA in the colleges. The One-Way-ANOVA results show no statistically significant difference in the responses of GA groups from different colleges with respect to their experiences of professional stimulation $F(129)=0.134 ; p>0.05$, inspiration $\mathrm{F}(129)=0.955 ; \mathrm{p}>0.05$ and mentoring $\mathrm{F}(129)=2.500 ; \mathrm{p}>0.05$ at the HEI. Intentional nurturing, supporting, guiding and challenging the GAs is missing (Nickelson, 2009; Trask, Marotz-Baden and Settles, 2009).

Although almost all the GAs disclosed their unhappiness about the mentoring at the colleges, most of the GAs had positive attitude towards their work experience as GAs. Interestingly, $81 \%$ of them agreed to the question "I have no regrets about the years I worked as a GA" (Table 3). Despite working for several years without promotion for professional and institutional development at the HEI, the GAs have less regret about their work experiences in the graduate assistantship. The findings match with the work of Park and Ramos (2002) who discovered that ECA "happy with their lot" despite the difficulties they face and the lack of rewards at work because " "the big picture' [Academician] is more important than just work-load, payment and status" for them (p. 53).

The participants explained that long-term professional capacity development is overlooked. The HEI are not positively impacting the GAs leading by example to follow their footsteps. These shortcomings encourage ECA to change their career plans at a time when it is not easy for the institutions to deal with such attrition. In the Eritrean HEI, there is no stringent and serious tenure-track screening system either for promotion or for demotion for the faculty; job security for the faculty is secured once recruited but this reinforces complacency and professional numbness. The GAs' major complaints in the colleges are linked to research, teaching and career 
promotions (Kosoko-Lasaki, Sonnino, and Voytko, 2006). GAs are looking for professional nurture in research and teaching to live up to the institutional standards. In the Eritrean HEI, GAs teach regardless of their competence to teach. However, teaching and research are the major components of the GAs' critical professional growth and the institutional performance gaps in the Eritrean HEI. The participants complained that there is no formal mentorship program at the colleges designed to support the GAs. A senior professor at one of the colleges remarked:

$G A$ is a student prepared for graduate school and the only way he can develop is to be able to obtain mentorship from the senior faculty and to follow what the senior professors do in their instruction, research and presentations of seminars; otherwise, what is the essence of having him in a department.

An associate dean explained that the colleges' efforts to ensure recognition, delegation, accountability and encouragement of GAs are not yet systematic and hardly materialized in practice. The ECA are relatively satisfied with their teaching roles as compared to their research roles (Fuller et al., 2008). The GAs lack independent as well as team research experience; but they are eager to conduct research in collaboration with the senior staff. The GA participants explained that mentoring ECA in research is very helpful in decreasing their sense of professional isolation, promoting teamwork and sense of confidence in conducting research (Katz and Coleman, 2001). But the participants remarked that research is almost the paralyzed arm of activity in their colleges, in which even the seniors are not active. A senior faculty said that informally the seniors are doing what is expected from them in terms of shaping the GAs' teaching skills, but in short of training the GAs in research skills. Out of the 133 GAs, $83 \%$ disagreed with the item that deals with they were mentored by the seniors in research skills (Table 1).

Despite the 'publish or perish' culture of HEI, there is very little ground for research and publication opportunities in their institutions. The major challenges expressed include the teaching loads of the faculty leave little room for research opportunities and made the colleges mainly teaching institutions. The seniors pointed out the lack of funding and basic research facilities including laboratories, internet connectivity and the absence of linkage with external partners were mentioned as the major obstacles related to the sluggish research activities in the colleges. However, funding follows a research project, because sound research proposals attract funding instead of faculty waiting to secure fund to develop research projects. Furthermore, the GAs indicated that the culture of teamwork in research and communicating the findings back to the faculty through seminars and workshops is missing in the colleges. One of the GAs claimed that "the more educated and experienced the seniors, [paradoxically] the more 'selfishly' they behave."

\section{The challenges hindering effective mentoring at the higher education institutions}

There are multitude challenges that are hindering effective mentoring at the HEI. The possible mentioning options for the ECA at the HEI depend on different facts. According to Cossa (2016), it is hard to find "recipe for organizing learning experiences for novice lecturers" (p. 1774). Factors hindering successful implementation of mentoring programs are often related to personal and institutional factors. The meta-analysis of related literature of mentoring in HEI from 1989-2014 by Fountain and Newcomer (2016), found a long list of factors linked to effective faculty mentoring. The list includes clearly stated purpose and goals, continuous evaluation of improvement, visible support from senior administration, adequate resources, inclusive design that instills mentoring as a cultural value and core institutional responsibility, alignment with organizational goals and objectives and orientations for both mentors and mentees concerning the dynamics of mentoring.

Though the senior faculty members attribute the sources of the excuses to factors beyond the capacity of the immediate "bosses" in the colleges, the GAs blame the college authorities for not doing enough to manage the things within their capacity. In addition, participants indicated that the attitude of the staff towards the significance of pairing senior-junior faculty for mentoring purpose is not welcoming. The lack of support and commitment from faculty and leadership to coordinate mentoring programs as a forum of professional development resulted in decreased dyadic engagement between senior and ECA. The apparent lack of coordination, teamwork spirit and good will from the senior faculty and the absence of associated incentives for the senior faculty members was highly emphasized. Most of all, human behavior is a function of motivation and motivating seniors can contribute to nurture motivated ECA. However, the GAs are blamed for not taking proactive initiatives to approach their seniors for a well-thought mentoring relationship.

The facts in Fig. 1 clearly demonstrate that the HEI in Eritrea have a huge responsibility to mentor the large number of GAs to build their professional competence in order to assume more responsibilities and effectively execute their work at the colleges. The large number of GAs need further training to live up to the expectations of the colleges. The GAs outnumber the senior faculty members in the HEI in Eritrea and this disproportionate number is a major limitation to establish one-to-one faculty mentoring in the HEI. Teferra (2016) remarked that "the problem of instability - in terms of disproportionate growth trajectory for young and aging academics" in the system of HEI is one of the major concerns (p. 1877). Even the handful most senior national and expatriate faculty are still at "work" simply because there is no retirement procedure in the system, otherwise they are too old for the job. Moreover, majority of the local seniors are master's degree holders. Thus, they need mentoring to mentor the GAs and further training to better and longer contribution to the HEI. The GAs described the prevailing qualities 
of leadership in the HEI as "outdated and trivial mechanisms of control. They further noted that the institutions do not work with them to create an environment of professional stimulation and inspiration.

\section{Possible options of junior faculty mentioning relationships at the Eritrean higher education}

The significance of faculty mentoring in the context of Eritrean HEI is unquestionable, but the mentoring options have to be contextualized to realities discussed. Determining a worthwhile type of mentioning relationship to effectively shape the attitude and skills of ECA at the HEI is quite challenging task. Thus, designing a situation specific mentoring relationship relevant to circumstantial realities is the best option (Bennett, 2010). The typical sample of the academic staff profile in the HEI portrayed in this paper clearly shows the glimpse of challenge. Taking the staffing context in Eritrean colleges into account and other leadership factors on ground as well as the fact that every senior faculty may not be a good mentor, the traditional way of one-to-one formal mentorship is not practical.

There are alternatives of faculty mentoring depending on the context and organizational culture. A number of mentoring models take place in HEI, including formal mentoring, informal mentoring, group mentoring, networking and peer mentoring (Hanover Research, 2014). However, each approach has a salient feature of its own uniqueness. Particularly, researchers show that poor dyadic fit in formal mentoring relationships results in more negative experiences. On the other hand, informal mentoring happening as a consequence of collegial interaction in the workplace nurtures the mentee's efficiency in harmonizing work and life balance as well as professional excellence (Thomas et al., 2015; Metzger et al., 2013). Thus, to determine the most appropriate and practical type of mentorship applicable to the context needs cautious decision.

The Hanover Research (2014) described group mentoring as "one mentor meets with multiple mentees at a time" (p.6) where the mentees usually have common purpose and interest congruent to the profession and expertise of the mentor. Group mentoring is especially effective in the Eritrean context where the mentoring resources are at a premium. One of the best options to the Eritrean HEI seems using "mentoring circles" approach. Mentoring circle relatively suits to the Eritrean context because it can be adapted innovatively to involve the mentors and mentees in small or large groups. Depending on the skill to be enhanced, an expert coaches a group of ECA on a regular basis.

A recent addition to the areas of mentoring in higher education is cascading mentoring. This approach is similar to the mentoring circle approach in some of its aspects. But cascading mentoring is relatively structured practice derived from informal mentoring tradition. This occurs when one mentor professionally empowers many mentees at a time. It is very appropriate in the context of the Eritrean HEI because it is highly recognized for its flexibility in practice. In cascading mentoring, mentees can service as mentors for their colleagues if the context requires. Another alternative is implementing peer mentoring in which a group of faculty will share experiences, common challenges, opportunities and any other issue of interest through regular circles of readings and research based discussions. This strategy creates an opportunity for a junior colleague to provide guidance and support to another colleague of the same status. However, personal issues may be overlooked in the peer-coaching strategy because the focus remains on major professional matters.

Depending on the situation, few senior faculty members can serve as mentors to help clusters of colleagues grouped according to their area of research interest and career development plans. This method is known as research cluster mentoring strategy which entails the mentees to carryout assigned duties and responsibilities through self-learning. A mentoring strategy similar to peer mentoring is peer mentoring networks that allows faculty members to interact across disciplines and areas of interest in the institutions. The professional networking allows the faculty not only to share ideas and experiences but also creates an opportunity to engage in an interdisciplinary collaborative and team spirited research projects.

\section{Conclusion}

Mentoring is a tool to enhance career functions and a long-term investment in personal and organizational development. Mentorship in HEI has the nature of transforming individuals, institutions, working conditions and challenges into opportunities. In Eritrea, mentoring the GAs is an essential homework of the HEI so that the colleges can stand on their own feet. Currently, the colleges are overwhelmed by the ECA and there is no any recognized mentoring practice in progress. The state of mentoring situation for the GAs in the colleges was described by GA participants as in a "state of inertia." The situation seems fertile ground for academic mediocrity in the $21^{\text {st }}$ century. The system does not seem to be worried to change the status quo, the national senior staffs and the expat staff are numb and the young are not proactively pushing. The lack of institutional initiative to nurture mentoring ECA at the HEI is a major challenge. Every academic year, the HEI are hiring expatriate faculties on contractual basis, which is not lasting solution. Properly mentoring, empowering and promoting the GAs on a merit based can prepare them to render better services than most of the fresh graduating or retired expatiate instructors. There is not noticeable national exit strategy from huge dependence on expatriate faculty and saving related costs. Therefore, it is time for the HEI to empower the GAs through all available means including mentoring 
and mapping out an exit strategy to get out of the vicious cycle of hiring expatriate instructors in mass.

\section{Recommendations for developing and sustaining effective faculty mentoring programs}

- A more detailed research coordinated by a team of seniors and GAs from all the HEI on the topic of induction and mentorship, including mentoring of students, is helpful to the colleges; because in HEI mentoring should go down to influence students and other campus community members.

- Group mentorship can be established for the GAs where experienced and devoted senior faculty can guide and supervise groups of GAs according their areas of interest and identified skills provided a deserving recognition and rewards for the senior faculty are available.

- Mentorship of novice employees has to be a tradition in HEI and other institutions for better institutional enculturation, harmony, retention and productivity at an individual, group and institutional levels.

- Some viable mentoring strategies relevant to the context are implied for future practice and research. However, for these suggestions to be effective, the departments need to reward mentors through stipends or other avenues of recognition whenever possible.

\section{References}

Alabia, G. and Abdulaib, M. (2016). Expectations and integration of early career academics into the teaching career: empirical evidence from Ghana. Studies in Higher Education, 41 (10), 1754-1771, http://dx.doi.org/10.1080/03075079.2016.1221654.

Armstrong, M. (2006). Handbook of human resource management practice (10 ${ }^{\text {th }}$ ed.). Kogan Page: London.

Bandura, A. (1977). Social learning theory. Upper Saddle River, NJ: Prentice Hall.

Bennett, R. (2010). The role of technology in the mentoring and coaching of teachers. Becta: Leading next generation learning.

Bolden, R. et al. (2003). A review of leadership theory and competency frameworks: Edited version of a report for chase consulting and the management standards centre. Centre for Leadership Studies: University of Exeter.

Boyden, K. M. (2000). Development of new faculty in higher education. Journal of Professional Nursing, 16 (2), 104-111.

Brown, M. C., Davis, G. L. \& McClendon, S. A. (1999). Mentoring graduate students of color: Myths, models and modes. Peabody Journal of Education, 74 (2), 105-118.

Clarke, M., Kenny, A., Loxley (2015). Creating a supportive working environment for academics in higher education: Country report Ireland. The Teachers' Union of Ireland and the Irish Federation of University Teachers.

Collaborative on Academic Careers in Higher Education. (2014). Benchmark Best Practices: Mentoring. Cambridge, MA: Harvard Graduate School of Education.

Cossa, E. F.R., Buque, D. C. \& Fringe, J. J. S. (2016). Teaching experience and expectations of early-

career academics in Mozambique: the case of Universidade Eduardo Mondlane, Studies in Higher Education, 41:10, 1772-1785, DOI: 10.1080/03075079.2016.1221655.

Ehrich, L. C., Hansford, B. \& Tennent, L. (2001). Closing the divide: Theory and practice in mentoring. Paper for ANZAM 2001 Conference, 'Closing the Divide', Auckland, New Zealand, 5-7 December 2001

Fountain, J. and Newcomer, K. E. (2016). Developing and sustaining effective faculty mentoring programs. Journal of Public Affairs Education, 22:4, 483-506, DOI: 10.1080/15236803.2016.12002262

Fuller, K., Maniscalco-Feichtl, M., \& Droege, M. (2008).The role of the mentor in retaining junior pharmacy faculty members. American Journal of Pharmaceutical Education, 72 (2), 1-5.

Hanover Research (January 2014). Faculty mentoring models and effective practices: Hanover University Report.

Inzer, L. D. and Crawford, C. B. (2005). A Review of Formal and Informal Mentoring: Processes, Problems, and Design. Journal of Leadership Education, (4):1, p. 31-50.

Katz, E. \& Coleman, M. (2001). Induction and mentoring of beginning researchers at academic colleges of education in Israel. Mentoring and tutoring: Partnership in Learning, 9 (3), 223-239).

Kee, J. E. and Newcomer, K. E. (2008). Transforming public and non-profit organizations: Stewardship for leading change. Vienna, VA: Management concepts.

Kosoko-Lasaki, O., Sonnino, R. E., \& Voytko, M. L. (2006). Mentoring for women and underrepresented minority faculty and students: Experience at two institutions of higher education. Journal of the National Medical Association, 98(9), 1449-1459.

Law et al. (2014). A checklist for the development of faculty mentorship programs. American Journal of Pharmaceutical Education, 78(5), 98.

McKimm J., Jollie, C. \& Hatter, M. (2007). Mentoring: Theory and practice. Retrieved from http://www.faculty.londondeanery.ac.uk/learning/eedback/files/entorin_Theory_and_Practic e.pdf.

Metzger et al. (2013). Essential elements for a pharmacy practice mentoring program. American Journal of Pharmaceutical Education, 77(2), 23. 
National Board for Higher Education, Eritrea (NBHE). (January, 2010). Higher Education Guidelines. Asmara, Eritrea.

Nickelson, C. W. (2009). Mentoring women graduate students: A model for professional psychology. Professional Psychology: Research and Practice, 40 (3), 284-291.

Osman, R. \& Hornsby, D. (2016). Communities and scholarship in supporting early-career academics at the University of the Witwatersrand. Studies in Higher Education, 41(10), 1835-1853.

Parise. M. R \& Forret, M. L (2008). Formal mentoring programs: The relationship of program design and support to mentors se perceptions of benefits and costs, Journal of Vocational Behavior, 72, 225240.

Park, C. \& Ramos, M. (2002). The donkey in the department? Insights into the graduate teaching assistant experience in the UK. Journal of Graduate Education, 3, 47-53.

Petryk, M. W. P. (2000).Department of chemistry and biochemistry teaching assistants handbook. University of Guelph, Ontario, Canada.

Subbaye, R. \& Dhunpath, R. (2016). Early-career academic support at the University of KwaZulu-Natal: towards a scholarship of teaching. Studies in Higher Education, 41 (10), 1803-1819, DOI: 10.1080/03075079.2016.1221657.

Sutherland, K. and Petersen, L. (2009). The Success and Impact of Early Career Academics in Two New Zealand Tertiary Institutions. AOTEAROA National Center for Tertiary Teaching Excellence.

Teferra, D. (2016). Conclusion: the era of mass early career academics and aging faculty - Africa's paradox, Studies in Higher Education, 41:10, 1869-1881, DOI: 10.1080/03075079.2016.1221650.

Teferra, D. (2016). Early career academics in Africa - induction into the teaching praxis. Studies in Higher Education, 41, (10), 1735-1740, http://dx.doi.org/10.1080/03075079.2016.1221651

Thomas, D., Lunsford, L.G., and Rodrigues, H. (2015). Early career academic staff support: evaluating mentoring networks. Journal of Higher Education Policy and Management, 37(3), 320-9.

Trask, B. S., Marotz-Baden, R. and Settles, B. (2009). Enhancing graduate education: Promoting a scholarship of teaching and learning through mentoring. International Journal of Teaching and Learning in Higher Education, $3(3), 438-446$.

Udegbe, I. B. (2016). Preparedness to teach: experiences of the University of Ibadan early career academics. Studies in Higher Education, 41 (10), 1786-1802.

Waxman, H. C., Collins, T. \& Slough, S. (2009). Lessons learned about mentoring junior faculty in higher education. Academic Leadership: The online journal, 7(2). Retrieved from http://www.academicleadership.org/emprical_research/626.

Wunsch, M. A. (1993). Mentoring probationary women academics: A pilot programme for career development. Studies in Higher Education, 18 (3), 349-362.

Zellers, D. F., Howard, V. M., \& Barcic, M. A. (2008). Faculty mentoring programs: Reenvisioning rather than reinventing the wheel. Review of Educational Research, 78(3), 552-588. 